\title{
Possible Sequential Transformation of a Series of Acidophils in the Pituitary Autografts in the Renal Capsule of Male Rats in Association with ACTH Cell
}

\author{
Fujio YOSHIMURA, Tsuyoshi SOJI, YASUchiKa TAKASAKI, \\ TSUNEAKI KUMAGAI AND SHIGENORI SATO \\ Department of Anatomy, Jikei University School of Medicine, \\ Nishishinbashi, Minato-ku, Tokyo 105
}

\begin{abstract}
Synopsis
In our electron microscopy, acidophils in the pituitary autografts placed in the renal capsules of immature male rats underwent a sequential transformation with the lapse of time: Within 3 and 6 days, all the somatotrophs packed with the large granules of about $350 \mathrm{~m} \mu$ diameter dispersed. The size and number of the granules in somatotrophs were quickly and markedly reduced with severe modification of cell shape. There was evidence during this time course that Siperstein's or Moriarty's corticotrophs might be synonymous with the stellate shape of acidophils with the arrangement of small granules $150-200 \mathrm{~m} \mu$ in diameter along the cell membrane. In other word, they may belong to a step of degranulation process of acidophils. The "acidophils of the small granule type" possibly related to ACTH production according to Yoshimura et al. (1974) were frequently detected in the grafts as elongated or irregularly shaped cells. Their minute granules $100-150 \mathrm{~m} \mu$ in diameter were also distributed in row in the cytoplasmic peripheral area. Gradual loss of the minute granules below $100 \mathrm{~m} \mu$ in diameter eventually made the acidophils to transform into agranular cells. Our own idea that ACTH secretion might correlate with a series of cells transforming along the acidophil-axis was indirectly supported by the present observation on pituitary grafts. On the other hand, basophils rapidly degenerated and died away. Ten and 20 days after autografting, the graft cells which might be principally composed of the cells of acidophil origin enormously proliferated through mitotic division, showing the homologous fine structure, without the normal cell individuality. They always contained three different size and shape of granules simultaneously. Significance of such a rapid and strong response of acidophils to the ectopic replacement in the immature male rats was discussed from the view-point of hypothalamic regulation to simple protein hormones.
\end{abstract}

It is well established that prolactin content of the pituitary grafts in the renal capsule increases conspicuously because of less responsibility of hypothalamic prolactin inhibiting factors to the grafts. Production of the pituitary tropic hormones except prolactin have been believed in general to be considerably suppressed by transplantation (Sanders and Rennels, 1959; Ahrén et al., 1962; Rubinstein and Ahrén, 1964;

$\overline{\text { Received for publication September }}$ 30, 1975.
Hjalmarson and Ahrén, 1964; Desclin and Flament-Durand, 1966 ; Evans, 1972). However, promoting effect of autografting to the adrenal weight in hypophysectomized rats was for the first time pointed out by Sanders and Rennels (1959), who demonstrated a considerable increase of adrenal weight over the normal range. Kendall and Allen (1968) reconfirmed the higher adrenal weight in hypohysectomizd rats (Pullman S-D ${ }_{4}$ and Holtzman S-D ${ }_{4}$ ) bearing the pituitary grafts than in intact rats, despite 
the absence of changes in plasma corticosterone content 10 days after autografting.

Morphological criteria to identify the ACTH secreting cells are still under controversy, notwithstanding the numerous cytological and immunohistochemical investigations (Kurosumi and Kobayashi, 1966; Breistedt, 1968 ; Siperstein and Miller, 1970 ; Phifer et al., 1970; Nakane, 1970; Baker et al., 1970; Pelletier and Racadot, 1971; Stefan and Dubois, 1972; Moriarty and Halmi, 1972; Stoeckel et al., 1973; Moon et al., 1973 and Erkokcak, 1973). The corticotroph has been regarded as a kind of acidophil, basophil, chromophobe and/or the other independent cell type. According to the photomicrographs presented by the above authors, however, the cells revealing the reactivity to the ACTH-antibody apparently assume quite variable, irregular, round, polygonal, polyhedral, ellipsoid or elongated shapes, occupying as much as $5-20 \%$ of the total number. Hence, difficulty is expected even in performing immunohistochemical technique. Ishikawa et al. (1972) separated small $(130-150 \mathrm{~m} \mu$ in diameter) and large granules ( $350 \mathrm{~m} \mu$ in diameter) from the pellets of isolated acidophils in rats. They found some ACTH activity in the small granules and strong GH activity in large ones. Sequential changes of acidophils in the pituitary grafts were electron microscopically demonstrated in this study with reconfirmation of our own idea that the ACTH secretion had some correlations with a series of cells transforming along the acidophil-axis.

\section{Materials and Methods}

Wistar-Imamichi young male rats (30 days of age) were hypophysectomized via the transauditory route under ether anesthesia. Removed pituitaries were immediately autotransplanted into the renal capsules of right kindneys of 23 rats. While many grafts survived in 20 rats, others became atrophic and substituted by fibroblasts in 3 rats. The cases of this retrogressive change of grafts probably due to the technical failure in the insertion were omitted. Twenty rats bearing the successful grafts in the renal capsules were divided into four groups. Five animals in each group were sacrificed after the intervals of $3,6,10$ and 20 days.

The piutitary tissues were removed from the thickened capsules and immediately fixed in $2 \%$ osmic acid in pH 7.4 phosphate buffer or in $\mathrm{pH} 7.4$ veronal acetate buffer for $2 \mathrm{hr}$. Fixation was followed by dehydration in a series of increasing concentration of cold ethanol, treatment with propylenoxyde for $10 \mathrm{~min}$, infiltration and embedding in epoxy resin 812. Thin sections were stained with a saturated uranyl acetate solution and then with the lead solution of Reynalds (1963). The sections were examined with a JEM 100B type electron microscope. An adjoining slice of about $2 \mu$ thickness was stained with toluidine blue solution for general light microscopic observation.

\section{Findings}

\section{Three days after autotransplantation}

Three days after autotransplantation the grafts were not sufficiently recovered from the temporal damage immediately after autografting: The graft cells were not compactly arranged with moderate penetration by the dilated blood capillaries. Each cell was distorted, leaving the opened intercellular space sometimes invaded by the collagen fibers. Cells of low density predominated in the peripheral area, but those of high density mostly occupied the central one. The compensatory response to autografting was an invasion by fibroblasts intermingled with the outgrowing parenchym cells ( $F$ in Fig. 3). Most acidophils in the grafts no longer maintained the typical characteristics of the somatotrophs (Figs. 1 and 2). Dispersion of the somatotrophs was rapidly carried out in this manner (Figs. 1 and 2). Reduction in size and number of granules was followed by the marked modification of cell shape. The normal maximal diameter of dense granules in the somatotrophs was approximately $350 \mathrm{~m} \mu$, while the elongated acidophils contained the small granules $150-250 \mathrm{~m} \mu$ in diameter $\left(A_{3}\right.$ in Fig. 2). As shown in Figure $2\left(A_{1}, A_{2}, A_{3}\right)$, the acidophils modified themselves to the 


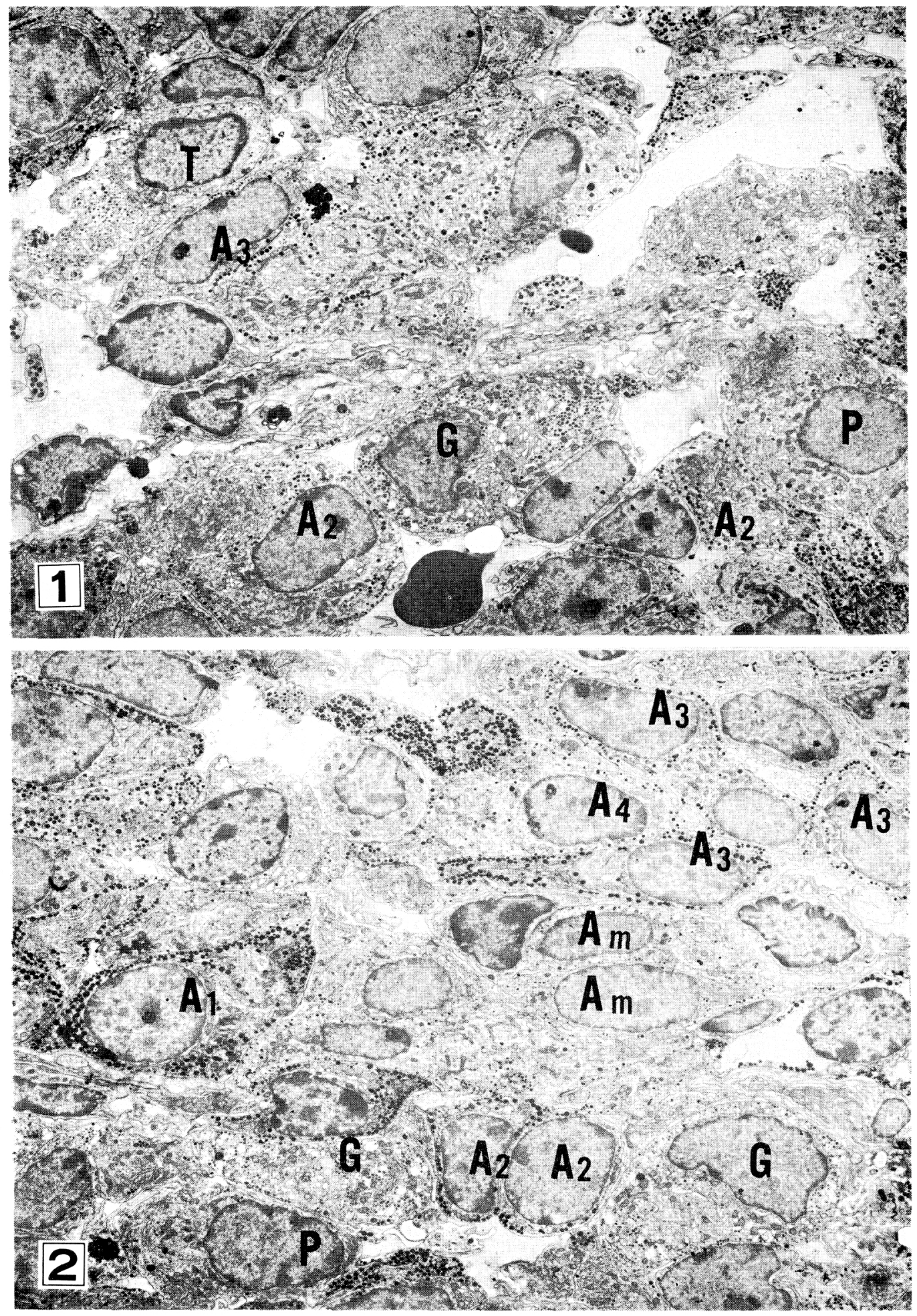

Figs, 1 and 2. Pituitary graft, 3 days after autotransplantation. $\times 3000 . T$, Thyrotroph; $G$, retrogressive gonadotroph; $\mathrm{P}$, prolactin cell; $\mathrm{Am}$, ambigous cell; $\mathrm{A}_{1}$, the first stage of transformation af acidophils; $\mathrm{A}_{2}$, the second stage, $\mathrm{A}_{3}$, the third stage; $\mathrm{A}_{4}$, the fourth stage. 

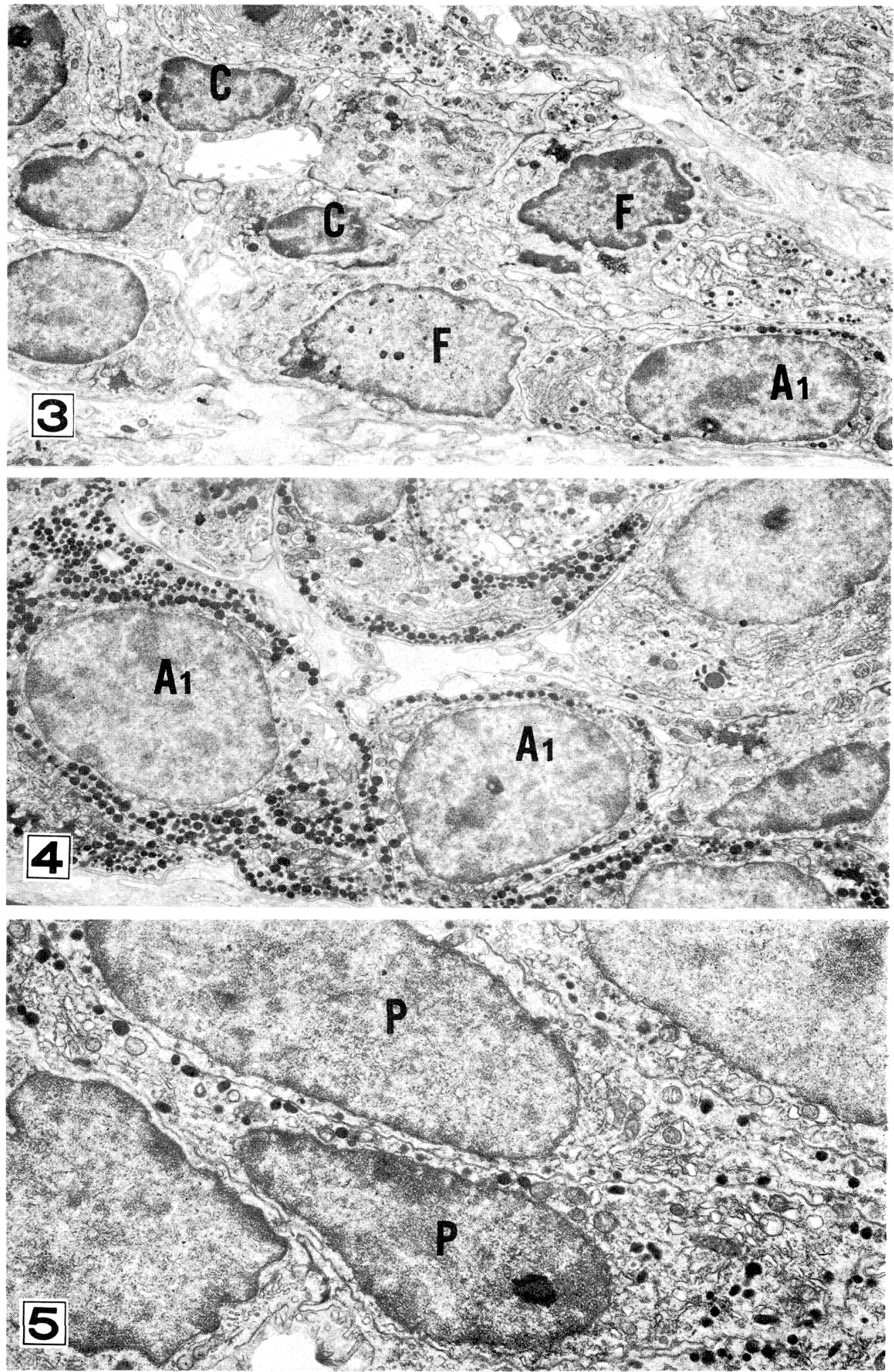

Figs. 34 and 5. Pituitary graft, 3 days after autotransplantation $\times 5200, \times 6000, \times 9000 . \quad C$, chromophobes (agranular follicular dell with microvilli); $F$, invading fibroblasts; $A_{1}$, the first stage of transformation of acidophil; $\mathrm{P}$, elongated prolactin cell containing the small polymorphic granules. 
elongated, polygonal or irregular shape. In the acidophils at this stage their small granules are usually arranged in row along the cell membrane (Fig. 4). This kind of acidophils are synonymous with the "elongated acidophils of the small granule type" denominated by Yoshimura et al. (1974). The angular or polygonal acidophils containing sporadically the minute granules below $200 \mathrm{~m} \mu$ in diameter were frequently seen ( $A_{3}$ in Fig. 2); they were distinguished with difficulty from the "ambiguous cells" whose direction for differentiation was vague whether they led to the acidophil or to the basophil (Am in Fig. 2). It was noteworthy that transplantation produced numerous ambiguous cells, either because of inhibited differentiation into the immature acdiophils or because of possible reversion of the acidophils to the ambiguous cells through degranulation. They were morphologically characterized by the low development of organelles, the some existence of small granules $(100-150 \mathrm{~m} \mu)$, and the elongation and irregularity of the cell shape. With a profound degranulation, the acidophils exhibited the parallel arrays of dilated ER or cisternae, and eventually became provided with complicated shape. On the other hand, so-called agranular follicular cells with microvilli surfacing the lumen remained unchanged ( $\mathrm{C}$ in Fig. 3). There was rather a slight proliferation by follicular cells in response to autografting. The agranular cells originating from the degranulated acidophis could not be distinguished from the possible migrating or pinched off follicular cells with slight granulation. After integral degranulation the elongated cells began to contain the polymorphic dense granules (so-called prolactin granules) (Fig. 5), although these cells cannot be reliably dicided whether they come from ambiguous cells or from degranulated acidophils. Within 3 days, the big prolactin granules did not sufficiently develop.

Basophils were susceptible to the retro- gressive change following autografting. Gonadotrophs were atrophic remarkably with a diminishment in number of round cisternae (Figs. 1 and 2). Healthy gonadotrophs with prominent Golgi apparatus (Ring-like distribution of Golgi vacuoles) and with anastomosing dilated ER remained occasionally in the grafts, but most gonadorophs were degenerated and thyrotrophs were infrequently encountered (Fig. 1).

\section{Six days after autotransplantation}

Within 6 days, the grafts grew in dimension to achieve more compact arrangement of their cells than after 3 days of the grafting. Pronounced degranulation in a series of acidphils resulted in their progressive transformation into agranular cells or at least the cells with scanty of small granules (Figs. 6 and 7). The enlarged ovoid cells containing only a small number of minute granules below $150 \mathrm{~m} \mu$ in diameter were demonstrated in Figs. 6 and $7\left(A_{3}, A_{4}\right)$. Some ovoid or polygonal cells became devoid of granules, turning into agranular acidphils (AA). Along with the loss of granules from some acidophils, their shape was modified to be polygonal again, developing the small polymorphic granules indicating initial formation of prolactin granules ( $\mathrm{P}$ in Fig. 7). These cells, however, showed the small size and low population in the male. The acidophils are identified as themselves based on the presence of large mitochondria and parallel distribution of rough ER. Thus, non-retrogressive but progressive changes of the grafts took place in a series of acidophils with a striking contrast with rapid retrogressive changes of the basophils.

Sequential transformation of the acidophils may be demonstrated in Fig. 8, favourable for our theory (Yoshimura et al., 1974). Instead of the typical somatotrophs filled with the large granules about $350 \mathrm{~m} \mu$ in the maximal diameter, there appeared some other type of acidophils initiating the transformation within 6 days (A in Fig. 8). 
They accumlated abundant granules 200$250 \mathrm{~m} \mu$ in the maximal diameter. These granules were only localized in row along the cell membrane but not in the central portion in the another acidophils. They are the cells of the first stage of transformation (abbreviated, $A_{1}$ ). The population of $A_{1}$ in the grafts can be roughly presumed on lowly magnified Figure 8 . In the next stage, the peripheral granules decreased in size, reaching $150-200 \mathrm{~m} \mu$ in diameter $\left(A_{2}\right.$ in Fig. 8). Since these cells took the stellate shape with the pocesses among the adhering cells, they resembled the ACTH-cells by Siperstein and Miller (1970) or Moriarty and Halmi (1972). These corticotrophs were reported to be located in the pituitaries of Long-Evans and Holtzman rats, but not in those of Wistar rats (Pelletier and Racadot 1971). However, it was conceivable that the Siperstein's corticotrophs detected by us in the pituitary grafts might belong to a kind of acidophil, despite no detection of this kind of cells in the Wistar strain of rats before transplantation. The peripheral granules in some another acidophils becames gradually reduced in size, reaching $100-150 \mathrm{~m} \mu$ in diameter. This is the third stage of transformation shown as $\mathrm{A}_{3}$. In the next stage, most granules were dispersed with the sporadical distribution of a small number of minute granules in their cell-bodies $\left(\mathrm{A}_{4}\right)$. As the final step of transformation, the degranulated acidophils terminated into the enlarged agranular acidophils (AA). The sequential changes of a series of acidophils have been thus demonstrated.

As the retrogressive change was enhanced in the basophils, gonadotrophs underwent

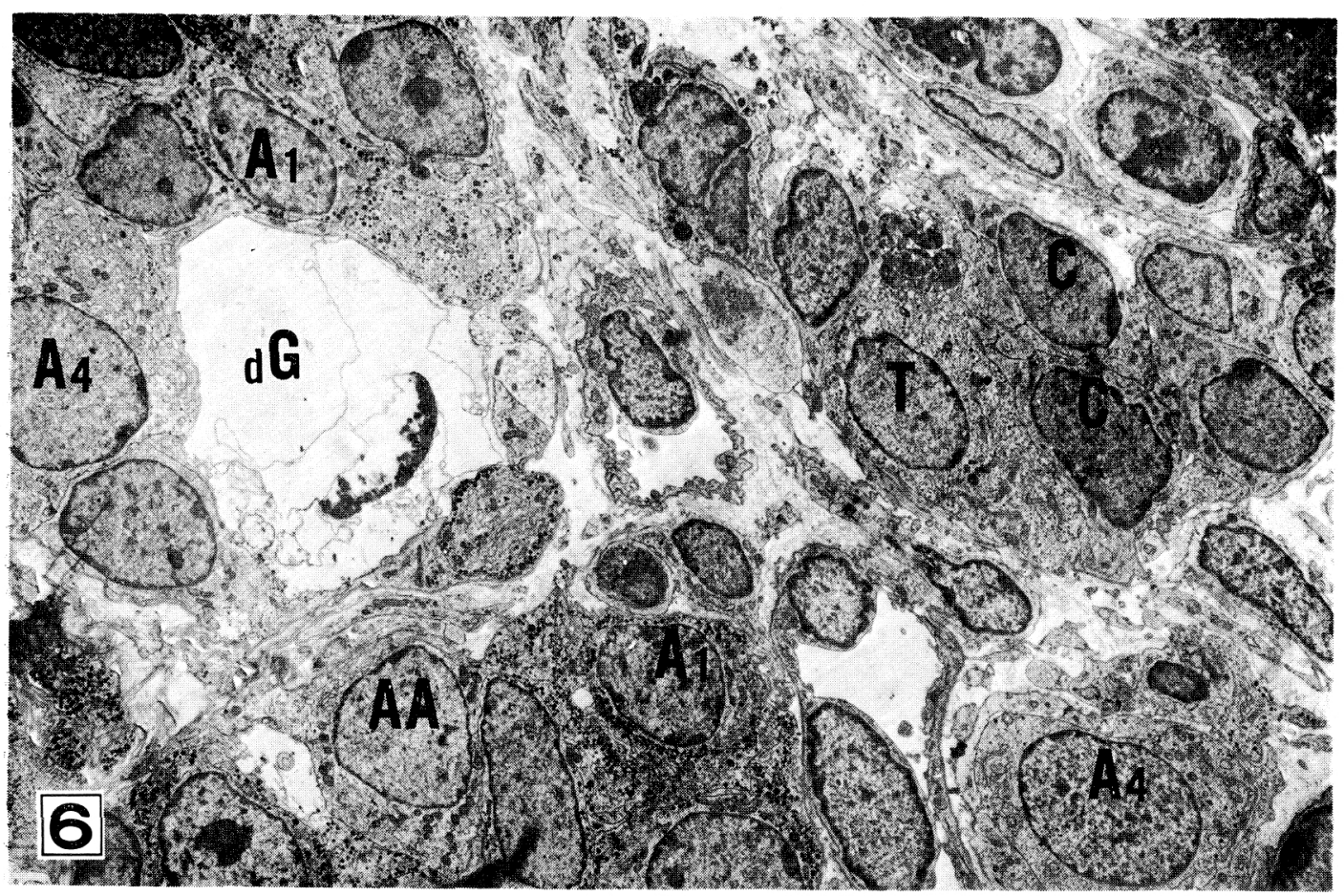

Figs. 6 and 7. Pituitary graft, 6 days after autotransplantation. $\times 2500, \times 4000$. dG, ghost cell originating from the degenerating gonadotroph; AA, agranular acidophil; C, chromophobe (follicular cell); $\mathrm{T}$, thyrotroph rarely detected; $\mathrm{A}_{1}$, the first stage of transformation of acidophil; $A_{3}$, the third stage; $A_{4}$, the fourth stage; iP, immature prolactin cell; P, prolactin cell. (Fig. 7, see next page) 


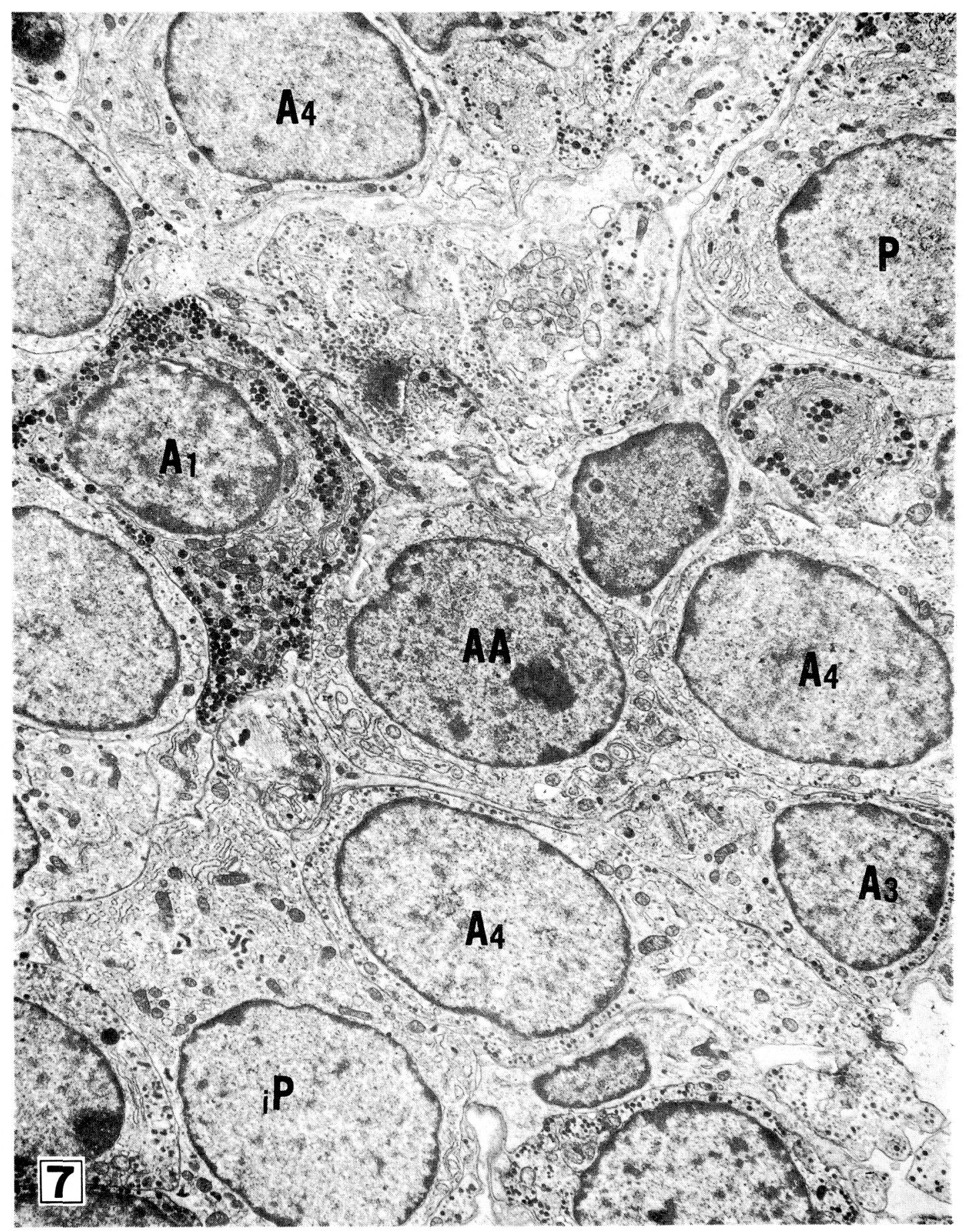




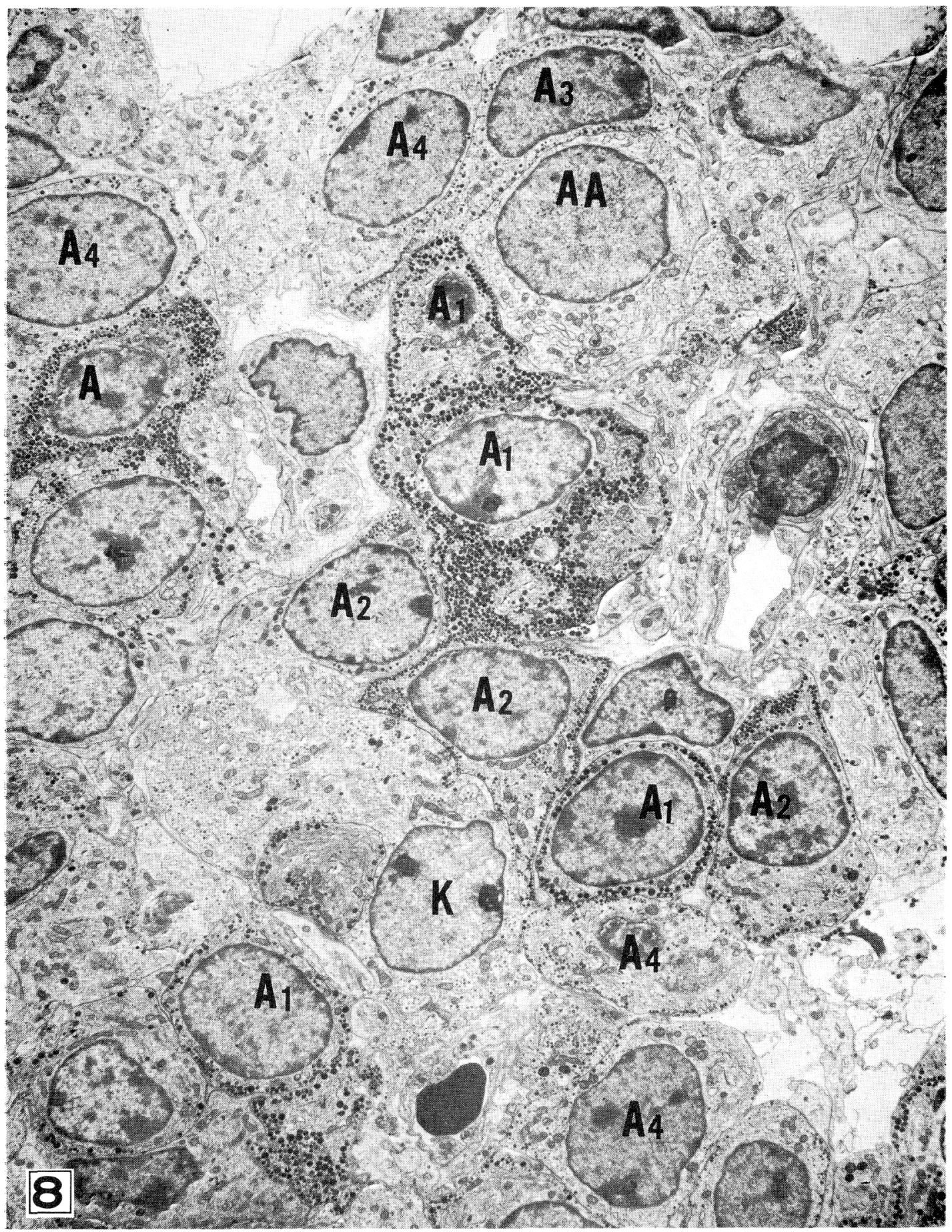

Fig. 8. Pituitary graft, 6 days after autotransplantation. $\times 3700, A_{1}, A_{1}, A_{2}, A_{3}, A_{4}$, and $A A$ show the sequence of transformation of acidophils from somatotrophs to agranular acidophils; $K$, Kurosumi's corticotroph. 


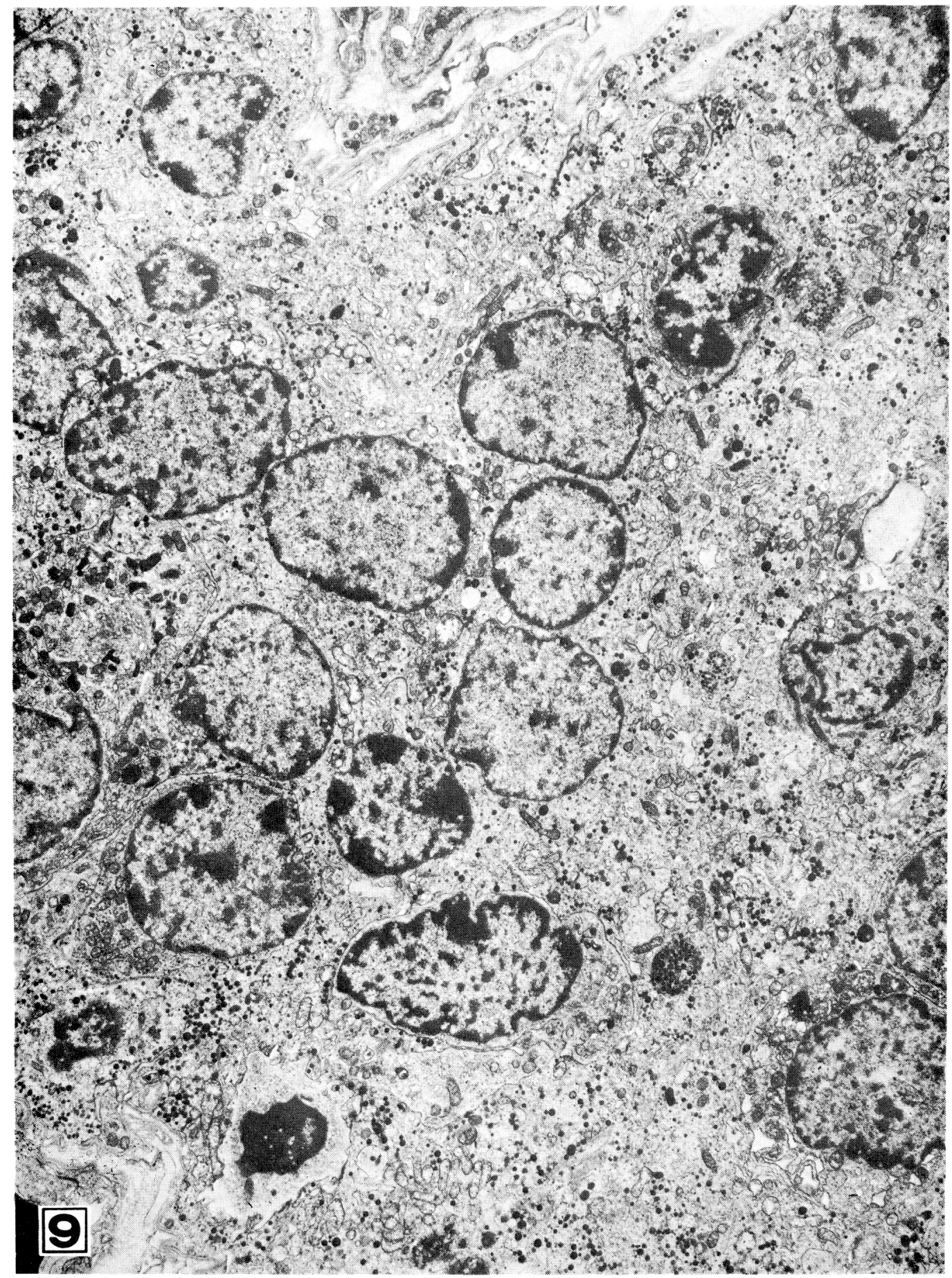

Figs. 9 and 10. Pituitary graft, 10 days after autotransplantation, $\times 5000, \times 8000$. The graft is filled with the cells showing the homologuous fine structure, and these cells contain concurrently three different sizes of granules. Proliferation of the homologous cells is more progressive in the adult females. (Fig 10, see the next page) 
serious degeneration or destruction, finally giving rise to the ghost cells ( $\mathrm{dG}$ in Fig. 6). Thyrotrophs occured exceptionally in the grafts ( $T$ in Fig. 6 ). The cells which may be identified as the corticotrophs denominated by Kurosumi and Kobayashi (1966) are infrequently detected ( $\mathrm{K}$ in Fig. 8), which were, in our observation, packed with the granules $200-250 \mathrm{~m} \mu$ in diameter of low density, sometimes taking the form of cored vesicles. Kurosumi's corticotrophs assume complicated shape, sometimes engulfing the other acidophils on a cut-surface. Their origination was, however, undecided in the present study.

\section{Ten days after transplantation}

In the interval of 10 days, the pituitary grafts showed a proliferative sign: Nuclei multiplied to form a cluster and the nuclear membrane often made incissurae (Fig. 9).
The shape of individual cells was vague because boundaries among them were indistinct but sometimes complicated. Degranulation of a series of acidophils was promoted with the consequent disappearance of the typical somatotrophs, and with a few remaining acidophlis containing only a small number of granules $200-250 \mathrm{~m} \mu$ in diameter. The graft cells showed the identical fine structure, losing their characteristic features as an independent cell, while the basophils almost died away.

These homologous cells may originate either from the indifferent acidophils or reversely from the degranulated acidophils according to our observation. These cells concurrently contained large (200-250 $\mathrm{m} \mu$ ), small $(100-150 \mathrm{~m} \mu)$ and polymorphic prolactin granules (over $400 \mathrm{~m} \mu$ in the maximal diameter) (Fig. 10). The acidophils differentiating along the acidophil-axis not only

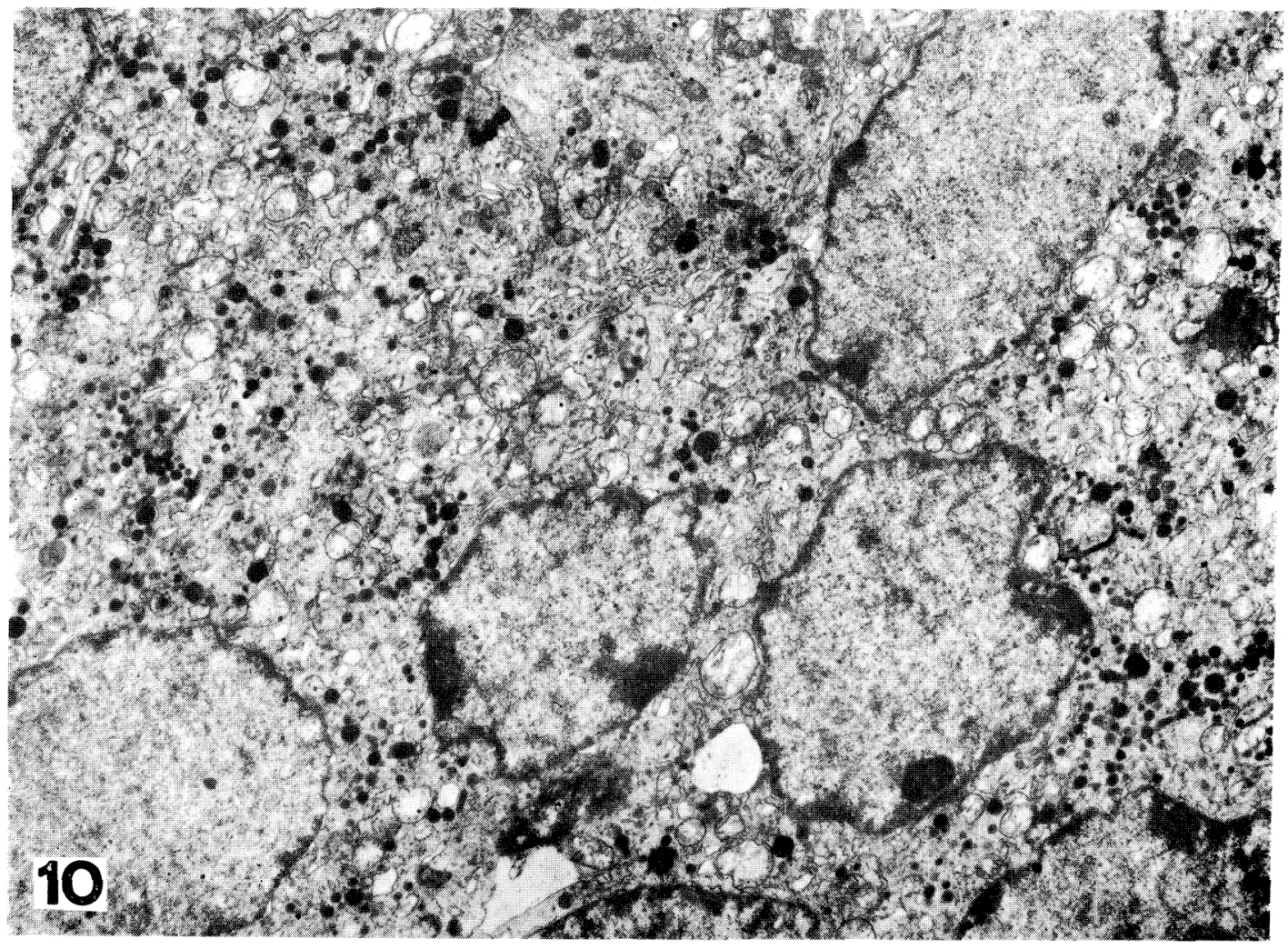


survived but also abnormally proliferated, while the basophils died away. Because of co-existence of three kinds of granules in one cell developing along the acidophilaxis, it can be postulated that all the intermingled granules are commonly related to the prolactin, ACTH and GH storage with reference to the previous bioassay data. The prolactin granules in the male rats, however, were never beyond $700 \mathrm{~m} \mu$ in the maximal diameter. Because of frequent mitotic figures, proliferation of the graft cells appears to be reliable. There were three independent acidophils containing small, large and prolactin granules respectively in addition to the closed ER, while the unusual cells containing concomitantly three different granules always showed the common dilatation of ER.

4. Twenty days after autotransplantation A series of acidophils became more susceptible to the generalization of fine structure by losing the cell individuality. Boundaries among them in the clusters were quite indistinct. Two important characteristics of fine structure are the dilation of round vesicles and concomitant existence of three kinds of granules. Compared to the changes in 10 days, the morphological generalization in the graft cells became more serious. In the grafts of the males, there were no typical prolactin serecting acidophils morphologically identified by the existence of polymorphic prolactin granules enclosed by the limiting membrane as seen in the females (Rennels, 1962). The mixed granules in each cell tended to decrease in number less than in 10 days.

\section{Discussion}

Siperstein and Miller (1970) and Moriarty and Halmi (1972) identified, electron microscopically and immunohistochemically, the corticotrophs as the stellate cells with the arrangement of the small granules 140-160 $\mathrm{m} \mu$ in row along the cell membrane. It is undecided, however, whether or not the two corticotrophs identified by the above two authors are intrinsically identical. Both the stellate shape and the arrangement of the granules in row along the cell membrane have generally been accepted as the criteria of ACTH-cells. Yoshimura et al. (1974), on the other hand, failed to confirm the ACTH cells as the independent cell type in adrenalectomized rats, but assumed them to be inherent in the "acidophils of the small granule type". Ishikawa et al. (1972) isolated the acidophils from the rat dissociated pituitary cells, and collected from them the free small granules $100-150 \mathrm{~m} \mu$ in the maximal diameter. These investigators recognized a detectable amount of $\mathrm{ACTH}$ in the small granules, although a large part of ACTH activity was lost during isolation.

In our observation of pituitary grafts, we demonstrated the entire course of degranulation of the acidophils from somatotrophs to agranular acidophils. In particular, development of "the acidophils of the small granule type" was related to the degranulating course of acidophils in the grafts. They were sometimes elongated, ovoid or irregularly shaped cells with the minute granules arranged in row at the peripheral area of cytoplasm. The corticotrophs by Siperstein and by Moriarty were detectable in the grafts, despite the failure of detection before autografting. We conceive that the corticotrophs by Siperstein and by Moriarty appear to be specific to Long-Evans and Holtzman rats under normal condition. In the graft, after gradual decrease in number and dimension of the granules in acidophils, their shape changed to be polyhedral or polygonal, and finally agranular cells developed, representing stellate shape on the cross section. There were enough morphological reasons to assume that such stellate cells originated from acidophils. Three or six days after autografting, the 
large granules $(350 \mathrm{~m} \mu)$ rapidly dispersed from some somatotrophs in harmony with the reduced pituitary GH content (Sanders and Rennels 1959), while the small granules $(150-250 \mathrm{~m} \mu)$ remained to be stored or rather tended to slightly increase in number, being compatible with the result of bioassay data indicating a transient rise of ACTH content (Kendall and Allen, 1968). Within 10 days, the grafts became filled with the uniform cells characterized by the concomitant existence of three different sizes of granules. These cells may originate chiefly from the degranulating acidophils.

Under condition in vivo, the granular size has been regarded as an indication of the kind of intracellular each hormone. The granules of $150 \mathrm{~m} \mu$ in diameter have been assumed to be the carriers of ACTH (Perdue and McShan, 1966; Ishikawa et al., 1971). Stable form of $\mathrm{GH}$ is stocked in the large free granules of $350 \mathrm{~m} \mu$ diameter (Ishikawa et al., 1971); prolactin is condensed in the polymorphic granules (Zanini and Ginnattasio, 1973). The change of size of three kinds of granules, in our opinion, indicates an inconstancy of activities of ACTH, GH and prolactin reported by the above investigators. Especially the number of the small granules in a series of acidophils seems to be in parallel with serum ACTH activity by the previous investigators. However, absence of assay data on pituitary ACTH in our present study made the question unsettled. Using adult female rats, Rennels (1971) made detailed electron microscopic observation on the pituitary grafts. Comparision of our results in the use of immature male rats with the observation by Rennels gave us an information that more rapid and more severe degranulation of acidophils took place in the immature males than in the adult females. Rennels did not pay special attention to the degranulation of acidophils, but his photomicrogrophs might show marked reduction in the size of granules in a certain acidophils.
Response of the basophils to the transplantation is quite different from that of a series of acidophils. Fate and maintenance of basophils are primarily regulated by the hypothalamus, while the acidophils tend to be autonomically regulated or may be subject to multiregulations. This may indicate the role of the hypothalamic releasing hormones (LH-RH) in exerting action on pituitary glucoprotein hormones during differentiation of basophils. Although the presence of an inhibiting factor for ACTH has not yet been built up by any investigators, present findings in the pituitary grafts may tentatively suggest a possible presence of ACTH inhibiting factor from a standpoint of morphology.

\section{References}

Ahrén, K., A. Arvill and A. Hjalmarson (1962). Endocrinologo 71, 176.

Baker, G.L., S. Pek, A.R. Midgley, Jr. and B.E. Gersten (1970). Anat. Rec. 166, 557.

Breistedt, J.H. (1968). Endocrinology 53, 1.

Desclin, L. and J. Flament-Durard (1966). Z. Zellforsch 96, 274.

Erkocak, A. (1973). Z. Mikros.-anat. Forsch. 87, 229.

Evans, J.S. (1972). Endocrinology 90, 123.

Hjalmarson, A. and K. Ahrén (1964). Acta Endocrin. 49, 17.

Ishikawa, H., T. Watanabe and F. Yoshimura (1971). Endocrinil. Japon. 18, 223.

Ishikawa, H., Y. Ohtsuka, F. Soyama and F. Yoshimura (1972). Endocrinol. Japon. 19, 215.

Kendall J.W. and C.F. Allen (1968). Endocrin. Exper. 2, 11.

Kurosumi K. and Y. Kobayashi (1966). Endocrinology 78, 7745 .

Moon, H.D., C.H. Li and B.M. Jennings (1973). Anat. Rec. 175, 529.

Moriarty C.C. and N.S. Halmi (1972). Z. Zellforsch. 132, 1.

Nakane P.K. (1970). J. Histochem. Cytorchem. 18, 9.

Pelletier G. and J. Racadot (1971). Z. Zellforsch. 116, 228.

Perdue J.F. and W.H. McShan (1966). J. Cell Biol. $15,159$.

Phifer, R.F., S.S. Spicer and D.N. Orth (1970). J. Clin. Endocrin. 31, 347.

Raynalds E.S. (1963). J. Cell Biol. 17, 208.

Rennels, E.G. (1962). Endocrinology 71, 713. 
Rubinstein, L. and K. Ahrén (1964). J. Endocrin. 32, 99.

Sanders A.E. and E.G. Rennels. (1959). Z. Zellforsch. 49, 263.

Siperstein E.R. and K.J. Miller (1970). Enaocrinology $86,451$.

Stoeckel, M.E., H.D. Dellmann, A. Porte, M.J. Klein and F. Stutinsky (1973). Z. Zellforsch. 136,
97.

Stefan Y. and M. Dubois (1972). Z. Zellforsch. 133, 1353.

Yoshimura, F., T. Soji, Y. Takasaki and Y. Kiguchi (1974). Endocrinol. Japon. 21, 297.

Zanini A. and G. Giannattasio (1973). Endocrinology 92, 349. 